\title{
Simian malaria in the Brazilian Atlantic forest: first description of natural infection of capuchin monkeys (Cebinae subfamily) by Plasmodium simium
}

Denise Anete Madureira de Alvarenga ${ }^{1}$, Anielle de Pina-Costa ${ }^{2,3}$, Taís Nóbrega de Sousa ${ }^{1}$, Alcides Pissinatti ${ }^{4,5}$, Mariano G Zalis ${ }^{6}$, Martha C Suaréz-Mutis', Ricardo Lourenço-de-Oliveira ${ }^{8}$, Patrícia Brasil², Cláudio Tadeu Daniel-Ribeiro 3,9 and Cristiana Ferreira Alves de Brito ${ }^{1 *}$

\begin{abstract}
Background: In Brazil, two species of Plasmodium have been described infecting non-human primates, Plasmodium brasilianum and Plasmodium simium. These species are morphologically, genetically and immunologically indistinguishable from the human Plasmodium malariae and Plasmodium vivax parasites, respectively. Plasmodium simium has been observed naturally infecting monkeys of the genera Alouatta and Brachyteles in a restricted area of the Atlantic Forest in the south and southeast regions of Brazil. However, its reported geographical distribution and the diversity of its vertebrate hosts may be underestimated, since available data were largely based on analyses by microscopic examination of peripheral blood, a method with limited sensitivity, considering the potential sub-patent feature of these infections. The present study describes, for the first time, the natural infection of $P$. simium in capuchin monkeys from the Brazilian Atlantic Forest.
\end{abstract}

Methods: Blood samples from 30 non-human primates belonging to nine species kept in the Primate Centre of Rio de Janeiro were collected. Fragments of spleen and liver from one dead monkey found in the neighborhoods of the Primate Centre were also analysed. Molecular diagnosis was performed by nested PCR (18SSU rRNA) and the amplified fragment was sequenced.

Results: Thirty per cent of the captive animals were infected with $P$. simium and/or $P$. brasilianum. The dead monkey tested positive for DNA of $P$. simium. For the first time, Cebinae primates (two specimens of genus Cebus and two of genus Sapajos) were found naturally infected by $P$. simium. The infection was confirmed by sequencing a small fragment of 18SSU rRNA.

Conclusion: The results highlight the possibility of infection by $P$. simium in other species of non-human primates whose impact could be significant for the malaria epidemiology among non-human primates and, if it becomes clear that this $P$. simium is able to infect monkeys and, eventually, man, also for the maintenance of transmission of human malaria in the context of a zoonosis in areas under influence of the Atlantic Forest.

Keywords: Simian malaria, Plasmodium simium, Plasmodium vivax, Plasmodium brasilianum, Plasmodium malariae, Cebinae, Molecular diagnosis, Atlantic forest

\footnotetext{
* Correspondence: cristiana@cpqrr.fiocruz.br

'Laboratório de Malária, Centro de Pesquisa René Rachou (CPqRR), Fundação

Oswaldo Cruz (Fiocruz), MG, Brazil

Full list of author information is available at the end of the article
} 


\section{Background}

Malaria, one of the major public health problems in the world, is a mosquito-borne disease caused by parasites of the genus Plasmodium that affects mammals, reptiles and birds [1]. Plasmodium species causing infection of nonhuman primates are of great interest because they may be naturally or accidentally transmitted to humans [2-7]. In Brazil, a country that holds the largest species diversified simian fauna of the planet, only two simian Plasmodium species have been found infecting non-human primates: Plasmodium brasilianum and Plasmodium simium. These species are morphologically, genetically and immunologically indistinguishable from the human malaria parasites Plasmodium malariae and Plasmodium vivax, respectively [8-11]. Both, P. brasilianum and P. simium are infective to human $[2,12]$.

Plasmodium brasilianum has a wide distribution in Central and South America, where it has been found in Brazil, Colombia, Venezuela, Panama, and Peru naturally infecting a large number of species belonging to all families of New World non-human primates, i.e., Aotidae, Atelidae, Cebidae, and Pitheciidae families [9,13]. In Brazil, excepting the arid portions in the northeast and savannah in the southeast, the territory range of $P$. brasilianum includes all regions and overlaps that of $P$. simium, which is restricted to the Atlantic Forest in the south and southeast [9]. Contrarily to P. brasilianum, P. simium has been detected infecting only two Atelidae genera: Alouatta (howler monkeys) and Brachyteles (woolly spider monkeys) $[9,14,15]$. However, most of the previous simian malaria surveys performed in the Atlantic Forest were based on microscopy of blood smears [9]. Given to the great diversity of primates in the Brazilian Atlantic Forest it is expected that, with the use of more sensitive diagnostic methods, the determination of the real rate of infection in monkeys and, eventually, the expansion of the list of potential hosts would be possible.

According to the National Malaria Control Program (PNCM), Secretary for Health Surveillance (SVS), Ministry of Health, from January 2006 to December 2013, 8,410 cases of malaria were reported in extra-Amazon region, 1,068 of them being autochthonous [16]. In 2013, from the 827 registered extra-Amazonian cases, 10.6\% (88 cases) were due to autochthonous transmission, corresponding to $0.05 \%$ of the total cases in Brazil [17]. In south and southeastern Brazil, human malaria transmission has been essentially eliminated or has been reported during scattered outbreaks of introduced cases, due to imported ones, for more than four decades [17-19]. However, few autochthonous human malaria cases and outbreaks have been reported associated with the Atlantic Forest environment, particularly in its mountain valleys in southeast Brazil $[9,17,19,20]$. In such environments, malaria transmission is supported by the bromeliad mosquito
Anopheles (Kerteszia) cruzii, which has been proved to be the natural vector of both human and simian malaria in south and southeast Brazil [9]. Therefore, Deane and colleagues in the 1990 s and others $[8,9,15,17,21]$ have suggested that human malaria in the Atlantic Forest could be a zoonosis where non-human primates are the reservoirs.

Autochthonous human malaria cases reported in the mountain valleys of the Atlantic Forest environment in Rio de Janeiro State motivated the search for natural simian plasmodial infections in this region [17]. The present study describes for the first time the natural infection of $P$. simium in the subfamily Cebinae by using molecular approaches.

\section{Methods}

\section{Origin of primate specimens}

Animals used in this study were captive primates from the Primate Centre of Rio de Janeiro (CPRJ). The CPRJ (IBAMA register number 458460) is a unit for wild monkey protection and is located in the municipality of Guapimirim, on the Serra dos Órgãos slopes (Figure 1), in an area under influence of the Atlantic Forest, about $100 \mathrm{~km}$ from the city of Rio de Janeiro. Serra dos Órgãos is part of the large coastal mountain chain in southeast Brazil named Serra do Mar. One wild animal, identified as an adult female of Alouatta guariba clamitans, was found dead nearby the CPRJ in December 2013 and an autopsy was performed, and spleen and liver fragments were included in the analysis. The present study was conduced in response to a demand of the Health Secretary of Rio de Janeiro State, to the Centro de Pesquisa, Diagnóstico e Treinamento em Malária (CPD-Mal), Fiocruz, in the context of an investigation on the autochthonous human cases registered in the surroundings of the CPRJ, and it had, therefore, the authorization of the Fiocruz Human Ethical Committee. As the handling of monkeys was exclusively done by CPRJ technicians, Fiocruz Animal Ethics Committee (CEUA) agreed to the protocol for sample collection.

\section{Samples collection and DNA extraction}

A total of 30 captive primates were sampled (Additional file 1) in November 2011. Of these, 18 were female (62\%); the average age was six years, median of seven years (1-14). The average weight was of 2,800 g (700-7,500 g). No animal was splenectomized at the time of sample collection. Approximately $2 \mathrm{ml}$ of blood were taken in vacuum tubes containing EDTA by femoral venipuncture. For just a few individuals sedation with Quetamina and Midazolan was required. The samples collection was performed by the Med Vet Alcides Pissinatti, the blood samples were frozen and send to the Malaria laboratory of the CPqRR, Fiocruz.

DNA extraction from blood samples was made using the Gentra Puregene Blood kit (Qiagen, Venlo, The 


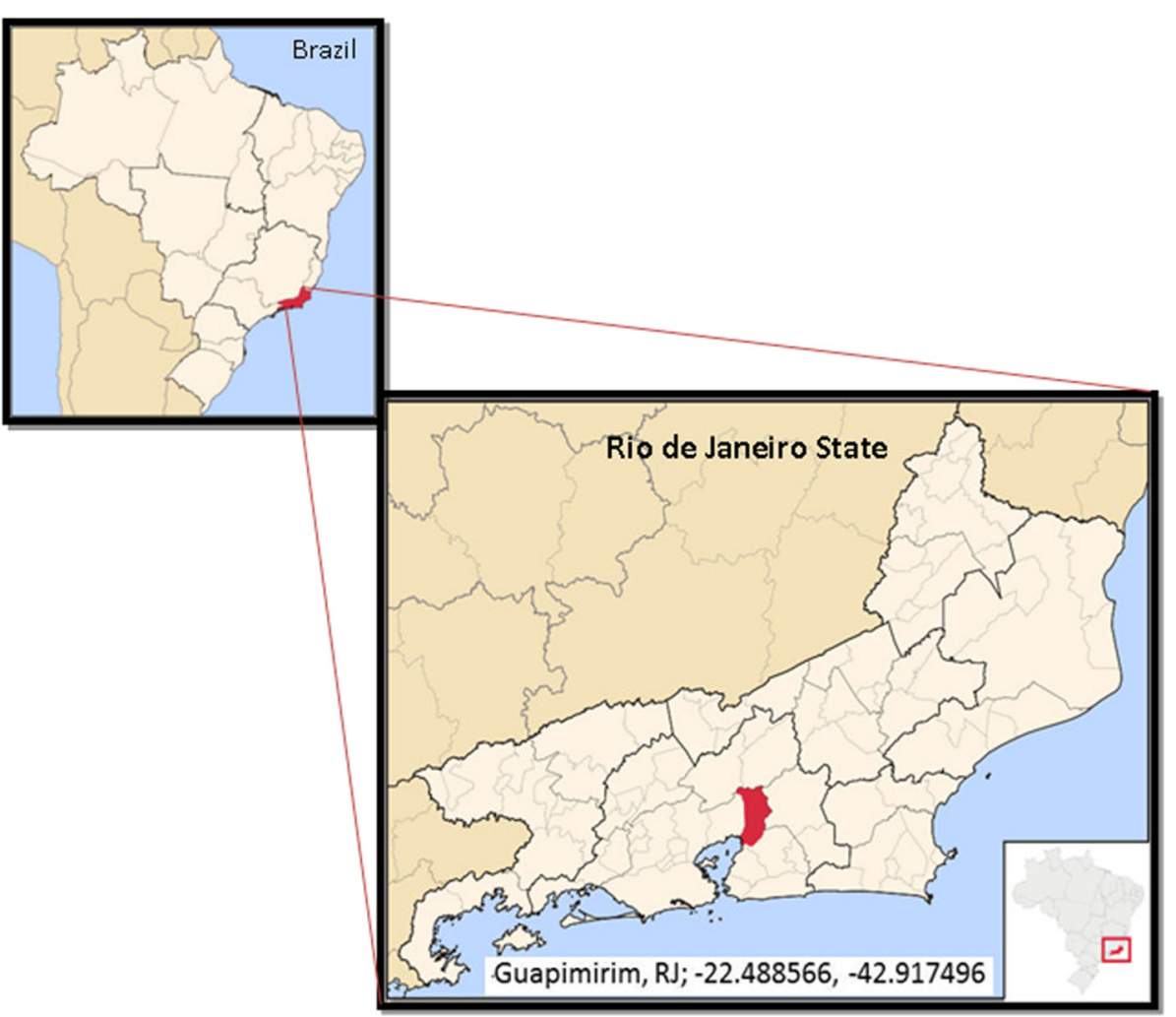

Figure 1 Maps of Brazil and of the State of Rio de Janeiro. Municipality of Guapimirim and its coordinates (red in Rio de Janeiro State map), in Serra dos Órgãos, where the Primate Centre of Rio de Janeiro (CPRJ) is located, in an area under influence of the Atlantic Forest, about $100 \mathrm{~km}$ from the city of Rio de Janeiro. Figure modified from Wikimedia Commons: http://commons.wikimedia.org/wiki/File:RiodeJaneiro_Municip_Guapimirim.svg.

Netherlands) according to manufacturer's recommendations. Fragments of spleen and liver from the dead monkey were used for DNA extraction using the Gentra Puregene kit (Qiagen, Venlo, The Netherlands) according to manufacturer's recommendations. The DNA was eluted in a $100 \mu \mathrm{L}$ volume and stored at $-20^{\circ} \mathrm{C}$ until it was used.

\section{Nested-PCR}

The samples were subjected to nested-PCR [22] using primers for identification of human Plasmodium species, targeting the small subunit of $18 \mathrm{~S}$ ribosomal RNA gene (18SSU rRNA). Briefly, all PCR reactions were performed in $20 \mu \mathrm{L}$ volumes containing $250 \mu \mathrm{M}$ each oligonucleotide primer, $10 \mu \mathrm{L}$ of Master Mix (Promega) (0.3 units of Taq Polymerase, $200 \mu \mathrm{M}$ each deoxyribonucleotide triphosphates and $1.5 \mathrm{mM} \mathrm{MgCl} 2$ ) and $2 \mu \mathrm{L}$ DNA. The PCR assays were performed using an automatic thermocycler (PTC-100TM v.7.0) (MJ Research Inc, USA) and the following cycling parameters were used: an initial denaturation at $95^{\circ} \mathrm{C}$ for $5 \mathrm{~min}$ followed by 24 cycles of annealing at $58^{\circ} \mathrm{C}$ for $2 \mathrm{~min}$, extension at $72^{\circ} \mathrm{C}$ for $2 \mathrm{~min}$ and denaturation at $94^{\circ} \mathrm{C}$ for $1 \mathrm{~min}$ followed by a final annealing incubation at $58^{\circ} \mathrm{C}$ for $2 \mathrm{~min}$ and extension at $72^{\circ} \mathrm{C}$ for $2 \mathrm{~min}$. The temperature was then reduced to $4^{\circ} \mathrm{C}$ until the samples were taken. The cycling parameters for the second round of PCR were the same as the first reaction, but instead 30 cycles of amplification were used.

To prevent cross-contamination, the DNA extraction and master mix preparation were performed in "parasite DNA-free rooms" distinct from each other. Furthermore, each of these separate areas has different sets of pipettes and all procedures were performed using plugged pipette tips. DNA extraction was performed twice at different days. Every PCR reaction had a negative control, where DNA has replaced by water and also positive controls for each pair of primers. The sources of genomic DNA samples that served as positive controls in the nested PCR assays are: i) P. falciparum DNA, strain 3D7 maintained in Malaria Laboratory (CPqRR-FIOCRUZ MINAS); (ii) DNA of patient with high parasitaemia for $P$. vivax and DNA of $P$. simium of a non-human primate with an acute infection and parasitaemia confirmed by optical microscopy (BL10); (iii) DNA of P. brasilianum of MR4 (Malaria Research and Reference Reagent Resource Center ATCC, USA).

The amplified fragments were visualized in electrophoresis on $1.5 \%$ agarose gel dissolved in $1 \mathrm{x}$ TAE buffer 

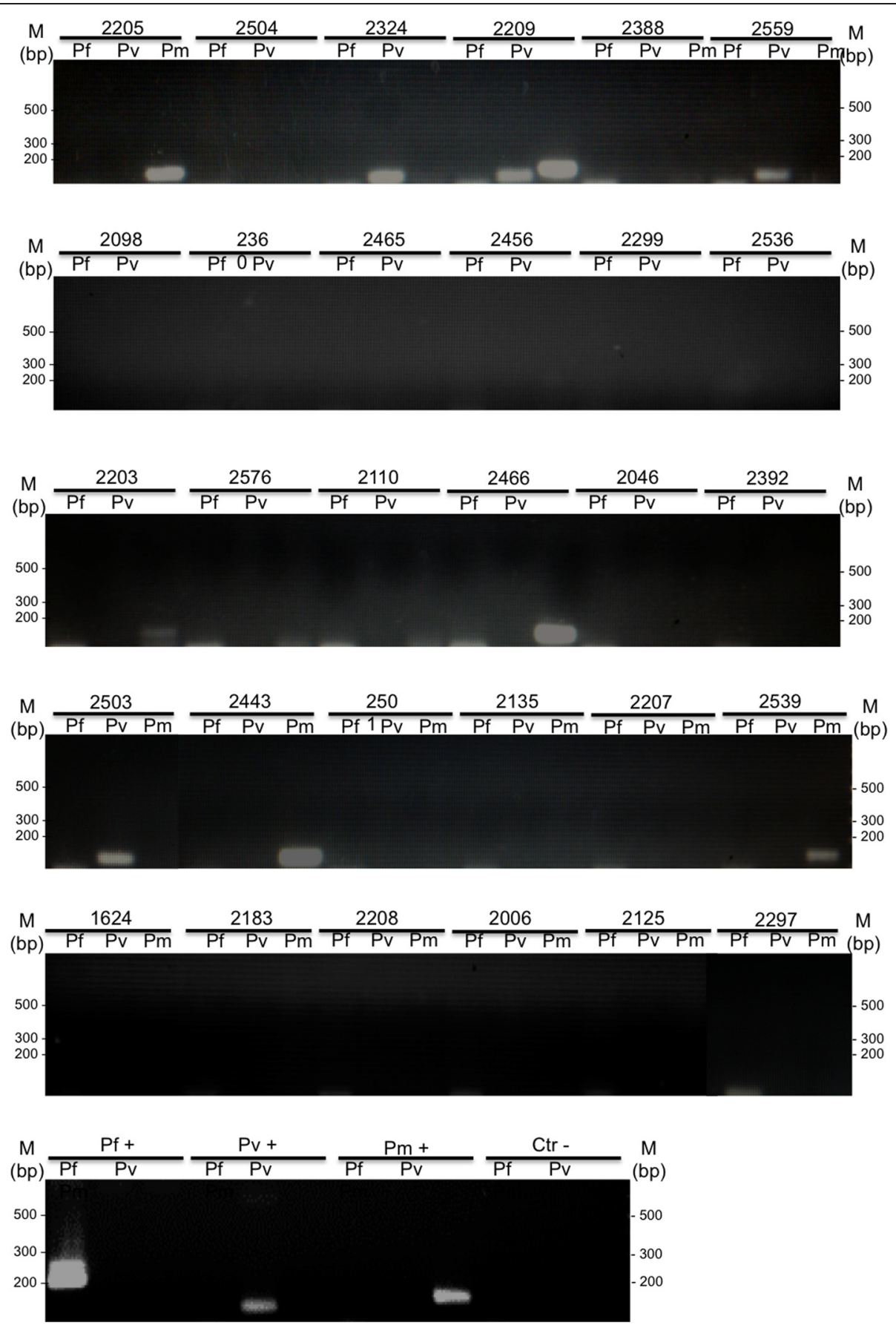

Figure 2 Molecular diagnosis of Plasmodium infection by nested-PCR of $\mathbf{3 0}$ non-human primate samples. Molecular diagnosis of Plasmodium infection by nested-PCR in 30 non-human primates from CPRJ using specific primers for P. falciparum (Pf), P. vivax (Pv) and Plasmodium malariae (Pm). Plasmodium simium was identified in Sapajus xanthosternos (2324), Sapajus robustus (2209) and Cebus sp. (2503 and 2559); and P. brasilianum was detected in Sapajus xanthosternos (2005 and 2539), Callicebus personatus (2466), Aotus nigriceps (2203), Sapajus robustus (2209) and Alouatta g. clamitans (2443). Agarose gels, 1.5\% stained with ethidium bromide. Numbers above gels indicated the non-human primates according to Additional file 1. Pf+, Pv + and Pm+: positive control (DNA species-specific) and Ctr -: negative control (without DNA), MM - 1 kb Plus Ladder.

(40 mM Tris-acetate, $1 \mathrm{mM}$ EDTA) with $5 \mu \mathrm{g} / \mathrm{mL}$ ethidium bromide (Invitrogen) in a horizontal system (Bio-Rad) at $100 \mathrm{~V}$ for about $30 \mathrm{~min}$. The gels were be examined under UV transilluminator (UVP - Bio-Doc
System it) and were filed under digital system. Electrophoresis was performed in a room specific for amplified DNA, with appropriated sets of pipettes and plugged pipettes tips. 


\section{Sequencing of PCR-amplified DNA}

For DNA sequencing, PCR products were purified using Purification Kit QIAquick (Qiagen) following manufacturer's procedure. Around $3 \mathrm{ng}$ of purified PCR products were amplified using $2.0 \mu \mathrm{M}$ of each primer (forward or reverse of species-specific primers of second reaction) and 1 $\mu \mathrm{L}$ of Big Dye terminator kit in a program of: $96^{\circ} \mathrm{C}$ for 1 min, 35 cycles of $96^{\circ} \mathrm{C}$ for $15 \mathrm{sec}$, the temperature of primer annealing for $15 \mathrm{sec}$ and $60^{\circ} \mathrm{C}$ for $15 \mathrm{sec}$. The fragments were precipitated using ammonium acetate, ressuspended in formamide HI-DI (Applied Biosystems) and electrophoretically separated in ABI 3730 DNA automatic sequencer.

\section{Data analysis}

The sequence data were analysed using the Blast program and the sequences aligned using the Clustal W and CAP3 programs in Bioedit package and also Muscle multiple alignment program [23]. The tree was constructed using the maximum likelihood method with Tamura 3parameter model [24] and 5,000 bootstrap replicates in MEGA 6.0 software [25].

\section{Results}

Molecular diagnosis was performed in samples from 30 non-human primates from the CPRJ, and nine samples (30\%) were found to be positive by nested-PCR: five samples were positive for $P$. brasilianum; three samples were positive for $P$. simium and one sample was positive for both $P$. simium and $P$. brasilianum (Figure 2). Negative controls never showed any amplified fragments and positive controls showed fragments with the expected sizes (Figure 2). Plasmodium simium was identified in Sapajus xanthosternos, Sapajus robustus and Cebus sp.; and P. brasilianum was detected in Sapajus xanthosternos, Sapajus robustus, Callicebus personatus, Aotus nigriceps and Alouatta g. clamitans (see Additional file 1). The dead wild monkey found nearby the CPRJ, sample MP1943, an Alouatta g. clamitans, was also found positive for $P$. simium by using DNA obtained from the spleen fragment and, with less intensity of amplification, from the liver fragment (Figure 3).

A species-specific fragment of 18SSU rRNA from $P$. simium identified in the molecular diagnosis was sequenced to confirm the infection for P. simium in monkeys from the Cebinae subfamily. Then the nucleotide sequence of $18 \mathrm{SSU}$ rRNA fragments from four infected animals $(2324,2559$, 2503, and MP1943) identified here were compared to $P$. vivax and other Plasmodium species sequences available at Genbank (Figure 4). From the alignment, the high genetic similarity between $P$. simium and $P$. vivax was evident (one difference out of $86 \mathrm{nt}$ ). It was also able to discern between the $P$. vivax/P. simium from the other species of Plasmodium. In addition, this alignment was used to

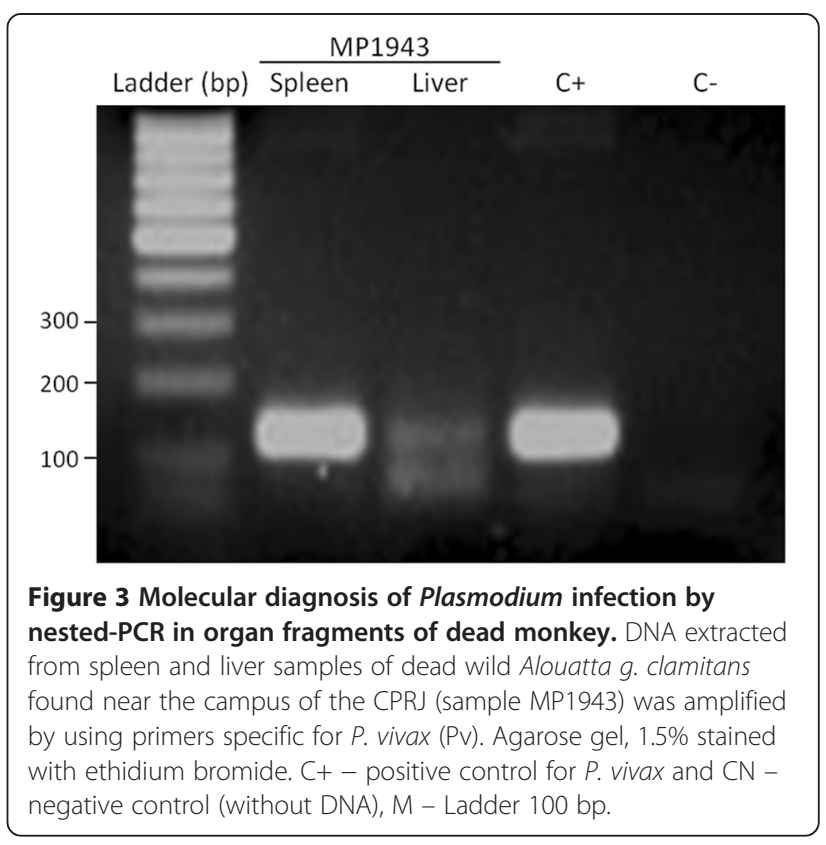

reconstruct the phylogenetic relationships of the simian and human Plasmodium. Plasmodium simium sequences clustered in a single branch. Moreover, all samples of $P$. simium are in the clade of $P$. vivax, reinforcing the genetic similarity between these parasites (Figure 5).

\section{Discussion}

By molecular analysis of blood samples of 30 captive primates from a primate center in southeastern Brazil, 30\% of the individuals were found infected with Plasmodium. Moreover, the dead monkey (Alouatta clamitans) found close to the CPRJ and also studied here showed infection by P. simium through detection of Plasmodium DNA in spleen and liver fragments. Interestingly, previous surveys based on microscopy of simian blood smears conducted in the same primate center (CPRJ) as well in other localities of the state of Rio de Janeiro failed to detect Plasmodium infections [26,27].

Although microscopic slides were not obtained, the presence of parasite DNA, even indicating possibly a low parasitaemia in the examined animals, points to the identification of a new natural host of $P$. simium: the capuchins monkeys. Capuchins monkeys are New World monkeys of the family Cebidae, subfamily Cebinae, that have the largest geographical distribution among the neotropical primates [28-32]. Prior to 2011, the subfamily Cebinae contained only a single genus, Cebus. However, recent studies have suggested the division of capuchin monkeys into two genera, Sapajus for robust, tufted capuchins and Cebus for untufted, gracile capuchins [33]. Cebus and Sapajus have been described infected only by $P$. brasilianum $[9,34]$. However, this study describes that primates belonging to three species from both genera 


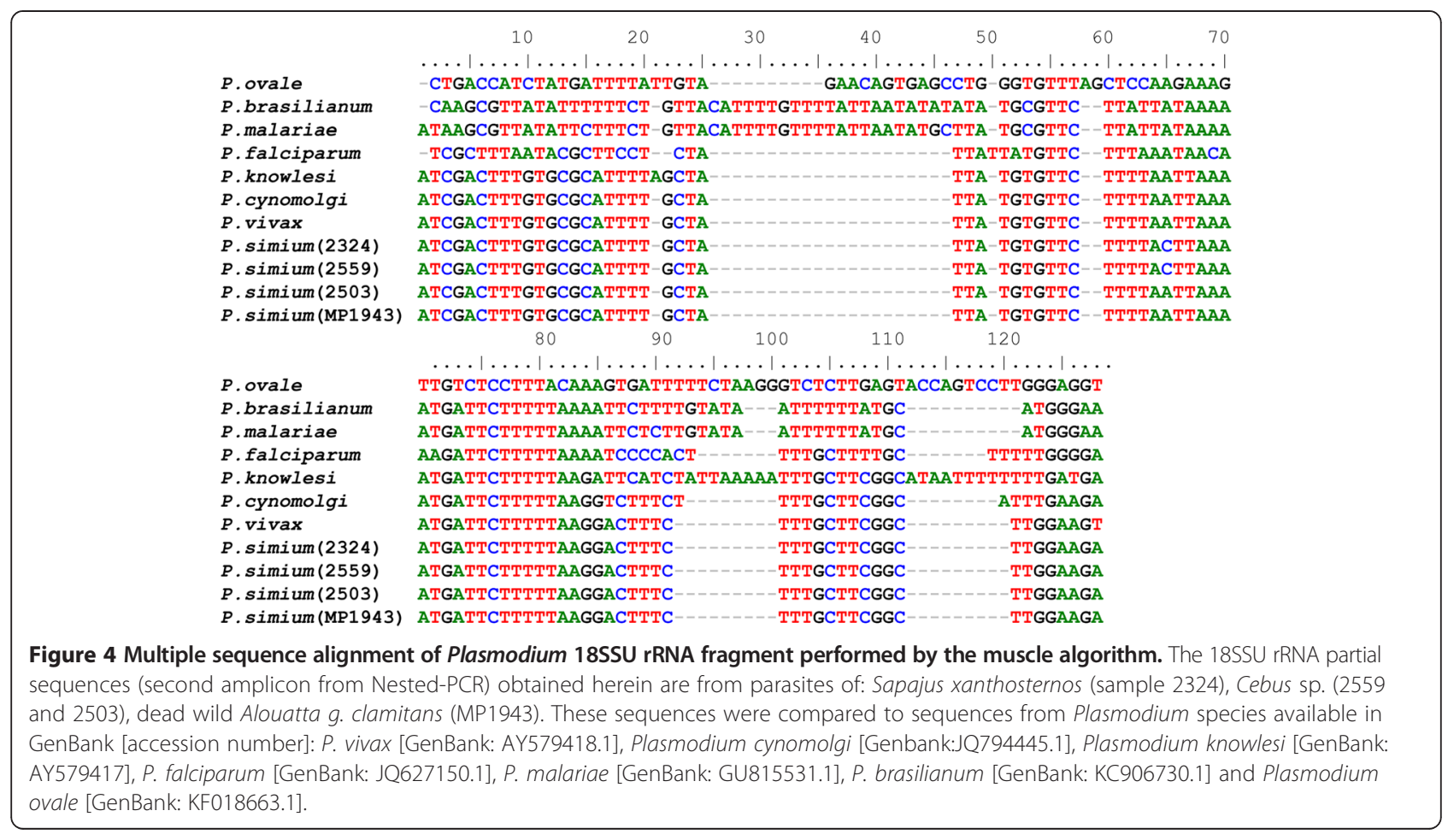

were found infected by $P$. simium. According to the literature, $P$. simium was described infecting only two species of genus Alouatta and one of Brachyteles primates [9,15]. Also, no evidence of experimental infection was obtained in splenectomized Cebus sp. inoculated with P. simium heavily parasitized blood sample [35]. Based on microscopy of blood smears, the natural infection rates for $P$. brasilianum in capuchin monkeys are usually very low compared to other Cebidae species, such as squirrel monkeys, as well as Pitheciidae and Atelidae species $[9,13]$. Thus, the finding of $P$. simium DNA in blood samples of capuchin monkeys from Rio de Janeiro suggests that these primates possibly undergoes Plasmodium infections with very low or transient parasitaemia.

Although the prevalence of Cebidae monkeys found infected in the CPRJ, which is located inside the Atlantic Forest, is similar to those reported for other species of monkeys found to carry Plasmodium parasites in the region $[9,15,21]$, it is still necessary to determine if captive monkeys were caught infected by Plasmodium or if the transmission has occurred at the CPRJ, facilitated by the simultaneous presence of the vector and infected monkeys. Plasmodium infection detected in one monkey born in CPRJ (monkey 2324), the naturally infected (dead)

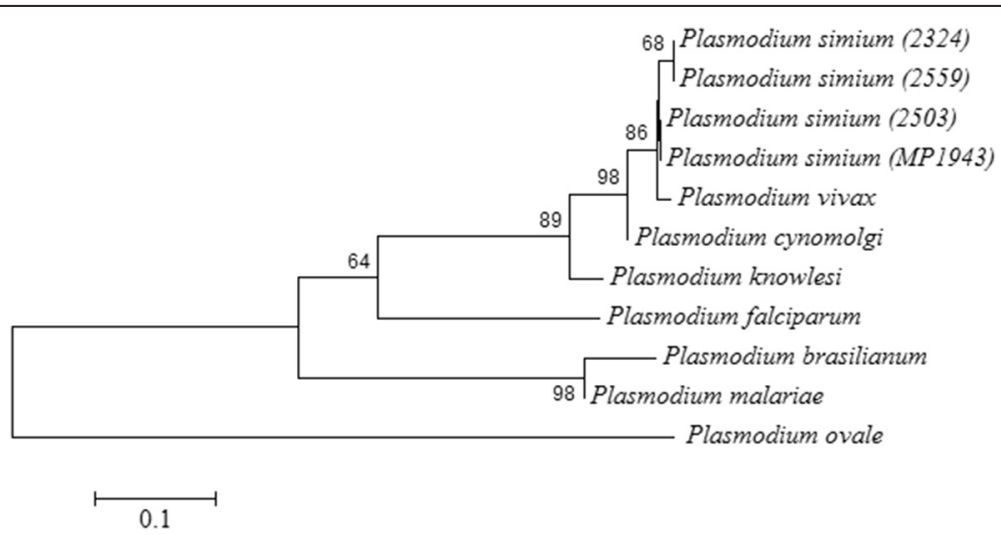

Figure 5 Topology of the phylogenetic tree of 18SSU rRNA. Topology of the phylogenetic tree of 18SSU rRNA with the four sequences of P. simium obtained from: Sapajus xanthosternos (2324), Cebus sp. (2503 and 2559) and death wild Alouatta g. clamitans (MP1943). The same sequences from the other species were used as in Figure 4. The tree was generated using the method of maximum likelihood and Tamura 3-parameter model with 5,000 replicates (bootstraps $>60 \%$ showed in the branches). 
wild monkey in the neighborhoods of CPRJ and the existence of malaria vectors such as An. (Ker.) cruzii, Anopheles (Nyssorhynchus) albitarsis and Anopheles (Nyssorhynchus) aquasalis in the region may support the latter hypothesis [36,37]. In addition, the high proportion of monkeys found carrying antibodies against blood forms and sporozoites of $P$. brasilianum and $P$. simium may either reinforce the hypothesis of an increased transmission in the CPRJ neighborhoods or suggest that the prevalence of Plasmodium infection may be much higher than expected in this area of Atlantic Forest [9,15,21,38].

As all measures to avoid contamination have been undertaken here and the PCR reactions were very well controlled (see Methods) the results presented here can not result from cross-contamination in the laboratory. Therefore, the present list of $P$. simium-susceptible, neotropical, non-human primate species might be incomplete because of the usual nature of sub-patent infections along with the limited sensitivity of the diagnostic methods used, that were mainly based on analyses of peripheral blood microscopy. The findings showed here are strengthened by those of Duarte et al. who described the occurrence of antibodies against the $P$. vivax circumsporozoite surface protein (CSP) in Cebus sp. from Brazil [11]. The presence of individuals from the Cebus genus carrrying antibodies against $P$. vivax $\mathrm{DBP}_{\mathrm{II}}, \mathrm{MSP}_{19}$ and $\mathrm{AMA} 1$ has also been identified by our group in monkeys from different areas (unpublished data).

New World simian Plasmodium are very closely related to human Plasmodium; P. brasilianum and P. simium are similar to the human $P$. malariae and $P$. vivax parasites, respectively. The sequencing of a small fragment of the18SSU rRNA encoding gene showed a high genetic similarity between $P$. vivax and $P$. simium, as demonstrated by Tazi and Ayala [39]. This high identity is also observed in the phylogenetic reconstruction of $P$. simium isolates studied here. It is important to notice that the small size of the sequenced fragment may hinder their ability to reproduce the phylogeny of the genus Plasmodium. Moreover, the high level of conservation in 18SSU rRNA among close species, such as $P$. vivax and $P$. simium, hamper the discussion if these species are distinct or not from each other. Many authors based on an analysis of different molecular targets, such as the conserved regions of the gene coding for the circumsporozoite surface protein (CSP) or mitochondrial genes have been suggesting the existence of two different species, $P$. simium and $P$. vivax, very closely related and their origin was through multiple host switches recently in the evolution [40-42].

The evolutionary history of $P$. vivax in the Americas is still very controversial. The most accepted hypothesis is that of post-Columbian origin, where $P$. vivax would have arrived with Europeans during the colonization of the
Americas $[43,44]$. In the New World, several evidences suggest a recent introduction of $P$. vivax $[43,45,46]$. The evolutionary history of $P$. vivax in the Americas was studied by analysing the mitochondrial genome variability of these parasites. Many different genetic groups circulating in South America were found, and they have probably originated from independent introductions [47].

Despite the data presented here is not sufficient to support a deep discussion about this subject, the evidence collected so far suggest that $P$. simium is possibly a different species from $P$. vivax, based especially on some differences on the morphology and, more recently, polymorphisms in some genomic sequences. However, additional genomic information on $P$. simium is still needed to support this hypothesis.

Taken together, the data reinforce the hypothesis that non-human primates of Atlantic Forest, including species which have never be incriminated before, such as the capuchins monkeys, could be acting as a reservoir for Plasmodium. Once autochthonous human cases of malaria are reported in those regions, the presence of possible wild reservoirs may have important implications for public health, due to close contact between humans and monkeys in some parts of the Atlantic Forest environment $[17,19]$.

\section{Conclusions}

The findings presented here might impact the knowledge on the epidemiology of the disease among human and non-human primates in the Brazilian Atlantic Forest. If it becomes clear that the same parasite can infect both humans and monkeys in this area, the presence of possible animal reservoirs may have important implications for public health [48] and areas of Atlantic Forest should be under strict surveillance for the possibility of a zoonotic pattern of malaria transmission. However, more studies are still needed to confirm this, particularly the detection of gametocytes in the monkeys and the identification of the same parasites circulating among the vectors and both hosts: human and simian. Due to the known close similarity between $P$. simium and $P$. vivax, the data reported here indicate that Cebus and Sapajus monkeys should have their susceptibility to $P$. vivax investigated in order to determine if they could represent new experimental models for studies with human Plasmodium, in addition to the Saimiri and Aotus neotropical monkeys recommended by the World Health Organization [49].

\section{Additional file}

Additional file 1: Description of 30 non-human primates studied and molecular diagnosis of Plasmodium.

Competing interests

The authors declare that they have no competing interests. 


\section{Authors' contributions}

CTDR, CFAB, PB, APC, MGZ, and RLO conceived the idea and participated in the study design. AP, PB, MCS, and APC were responsible for sample collection. DAMA and TNS carried out the experiments and analysed the data. CFAB, CTDR, RLO, and DAMA drafted the manuscript. All authors read, corrected and approved the final manuscript.

\section{Acknowledgements}

The authors thank the PDTIS sequencing facilities of FIOCRUZ, Gabriela Assis and Lara Cotta Amaral for assistance on sequencing experiments and the team of the Primate Centre of Rio de Janeiro (CPRJ/INEA). The authors are also grateful to the Parc Zoologique et Botanique Ville de Mulhouse, France; to Jean Marc Lernould, Zoological Society for the Conservation of Species and Populations - München Germany; and to Dr Roland Wirth and the Conservation International $(\mathrm{Cl})$, for cooperation in the program for reproduction of Sapajus from the Brazilian Atlantic Forest. CFAB, CTDR and RLO are supported by the Conselho Nacional de Desenvolvimento Científico e Tecnológico (CNPq) (through a Research Fellowship). CTDR and RLO are grateful for the support of the Faperj as Cientistas do nosso Estado. APC and DAMA received fellowships from the Coordenação de Pessoal de Ensino Superior (Capes). The study received financial support from the Secretary for Health Surveillance (SVS) through the Global Fund.

\section{Author details}

'Laboratório de Malária, Centro de Pesquisa René Rachou (CPqRR), Fundação Oswaldo Cruz (Fiocruz), MG, Brazil. ${ }^{2}$ Instituto Nacional de Infectologia (INI), Ambulatório de Doenças Febris Agudas, Fiocruz, RJ, Brazil. ${ }^{3}$ Centro de Pesquisa, Diagnóstico e Treinamento em Malária (CPD-Mal), Fiocruz, RJ, Brazil. ${ }^{4}$ Centro de Primatologia do Rio de Janeiro (CPRJ/INEA), Rio de Janeiro, RJ, Brazil. ${ }^{5}$ Centro Universitário Serra dos Órgãos (UNIFESO), Rio de Janeiro, RJ, Brazil. 'aboratório de Virologia Molecular, Hospital Universitário Clementino Fraga Filho, Universidade Federal do Rio de Janeiro, Rio de Janeiro, RJ, Brazil. ${ }^{7}$ Instituto Oswaldo Cruz, Laboratório de Doenças Parasitárias, Fiocruz, RJ, Brazil. ${ }^{8}$ Instituto Oswaldo Cruz (IOC), Laboratório de Transmissores de Hematozoários, Fiocruz, RJ, Brazil. ' ${ }^{2}$ Laboratório de Pesquisa em Malária (IOC), Fiocruz, RJ, Brazil.

\section{Received: 21 October 2014 Accepted: 3 February 2015}

\section{Published online: 18 February 2015}

\section{References}

1. Perkins SL, Austin CC. Four new species of Plasmodium from New Guinea lizards: integrating morphology and molecules. J Parasitol. 2009;95:424-33.

2. Deane LM, Deane MP, Ferreira Neto J. Studies on transmission of simian malaria and on the natural infection of man with Plasmodium simium in Brazil. Bull World Health Organ. 1966;35:805-8.

3. Arruda ME, Nardini EH, Nussenzweig RS, Cochrane AH. Sero-epidemiological studies of malaria in indian tribes and monkeys of the Amazon basin of Brazil. Am J Trop Med Hyg. 1989;4:379-85.

4. Carréri-Bruno GC, Ciaravolo RM, Pereira M. Malaria acquired during entomological research in the Serra do Mar, southeastern region of Brazil. Rev Saude Publica. 1995:29:142-3.

5. Singh B, Kim Sung L, Matusop A, Radhakrishnan A, Shamsul SS, Cox-Singh J, et al. A large focus of naturally acquired Plasmodium knowlesi infections in human beings. Lancet. 2004;363:1017-24.

6. Ta TH, Hisam S, Lanza M, Jiram Al, Ismail N, Rubio JM. First case of a naturally acquired human infection with Plasmodium cynomolgi. Malar J. 2014;13:68.

7. Yusof R, Lau YL, Mahmud R, Fong MY, Jelip J, Ngian HU, et al. High proportion of knowlesi malaria in recent malaria cases in Malaysia. Malar J. 2014:13:168.

8. Coatney GR. The simian malarias: zoonoses, anthroponoses, or both? Am J Trop Med Hyg. 1971;20:795-803.

9. Deane LM. Simian malaria in Brazil. Mem Inst Oswaldo Cruz. 1992;87 Suppl 3:1-20.

10. Leclerc M, Hugot J, Durand P, Renaud F. Evolutionary relationships between 15 Plasmodium species from new and old world primates (including humans): an 18S rDNA cladistic analysis. Parasitology. 2004;129:677-84.

11. Duarte AM, Porto MA, Curado I, Malafronte RS, Hoffmann EH, de Oliveira SG, et al. Widespread occurrence of antibodies against circumsporozoite protein and against blood forms of Plasmodium vivax, P. falciparum and $P$. malariae in Brazilian wild monkeys. J Med Primatol. 2006;35:87-96.
12. Garnham PCC. Malaria parasites and other haemosporidia. Oxford: Blackwell; 1966.

13. Lourenço-de-Oliveira R, Deane LM. Simian malaria at two sites in the Brazilian Amazon. I - The infection rates of Plasmodium brasilianum in non-human primates. Mem Inst Oswaldo Cruz. 1995;90:331-9.

14. Deane LM, Ferreira Neto J, Sitônio JG. A new natural host of Plasmodium simium and Plasmodium brasilianum: the woolly spider monkey. Rev Inst Med Trop Sao Paulo. 1968;10:287-8

15. Duarte AM, Malafronte RS, Cerutti C, Curado I, de Paiva BR, Maeda AY, et al Natural Plasmodium infections in Brazilian wild monkeys: reservoirs for human infections? Acta Trop. 2008;107:179-85.

16. SIVEP [www.saude.gov.br/svs].

17. Pina-Costa A, Brasil P, Santi SM, Araujo MP, Suárez-Mutis MC, Santelli AC, et al. Malaria in Brazil: what happens outside the Amazonian endemic region. Mem Inst Oswaldo Cruz. 2014;109:618-33.

18. Deane LM. Malaria studies and control in Brazil. Am J Trop Med Hyg 1988:38:223-30.

19. Oliveira-Ferreira J, Lacerda MV, Brasil P, Ladislau JL, Tauil PL, Daniel-Ribeiro CT. Malaria in Brazil: an overview. Malar J. 2010;9:115.

20. Miguel RB, Peiter PC, Albuquerque H, Coura JR, Moza PG, Costa Ade P, et al. Malaria in the state of Rio de Janeiro, Brazil, an Atlantic Forest area: an assessment using the health surveillance service. Mem Inst Oswaldo Cruz. 2014;109:634-40.

21. Yamasaki T, Summa ME, Neves DV, de Oliveira SG, Gomes AC. Natural Plasmodium infections in Brazilian wild monkeys: reservoirs for human infections? Acta Trop. 2008;107:179-85.

22. Snounou G, Viriyakosol S, Jarra W, Thaithong S, Brown KN. Identification of the four human malaria parasite species in field samples by the polymerase chain reaction and detection of a high prevalence of mixed infections. Mol Biochem Parasitol. 1993:58:283-92.

23. Bioedit (http://www.mbio.ncsu.edu/bioedit/bioedit.html).

24. Tamura K. Estimation of the number of nucleotide substitutions when there are strong transition-transversion and $\mathrm{G}+\mathrm{C}$-content biases. Mol Biol Evol. 1992;9:678-87.

25. Tamura K, Peterson D, Peterson N, Stecher G, Nei M, Kumar S. MEGA5: molecular evolutionary genetics analysis using maximum likelihood, evolutionary distance, and maximum parsimony methods. Mol Biol Evol. 2011;28:2731-9.

26. Lourenço-de-Oliveira R. Natural infection of golden lion tamarin, Leontopithecus rosalia, with Trypanosoma cruzi in the state of Rio de Janeiro. Mem Inst Oswaldo Cruz. 1990;85(I):15.

27. Moreira GV, Peixoto CMS, Ziccardi M, Oliveira RL, Castro MG, Dionísio DF, et al. Prevalência de Trypanosoma cruzi, Trypanosoma minasense e de anticorpos contra arbovírus em primatas não humanos (Callithrichidae) em cativeiro. Rev Bras Med Vet. 2000;22:252-4

28. Fragaszy DM, Visalberghi E, Fedigan LM. The complete Capuchin - the biology of the genus Cebus. Cambridge: Cambridge University Press; 2004.

29. Izawa K. Foods and feeding behavior of wild black-capped capuchin (Cebus apella). Primates. 1979;20:57-76.

30. Freese CHE, Oppenheimer JR. The Capuchin Monkeys, Genus Cebus. In: A. \& R Mittermeier, editor. Ecology and behavior of neotropical primates. Volume 1. 1st ed. Rio de Janeiro: Academia Brasileira de Ciências; 1981. p. 331-90.

31. Brown A, Chalukian S, Malmierca L. Habitat y alimentacion de Cebus apella en el N.O. Argentino y la disponibilidad de frutos en el dosel arboreo. Revista del Museuo Argentino de Ciencias Naturales. 1984;13:273-80.

32. Fedigan LM. Vertebrate predation in Cebus capucinus: meat eating in a Neotropical monkey. Folia Primatol. 1990:54:196-205.

33. Alfaro JW, Silva Jr JD, Rylands AB. How different are robust and gracile capuchin monkeys? An argument for the use of Sapajus and Cebus. Am J Primatol. 2012;74:273-86.

34. Araújo MS, Messias MR, Figueiró MR, Gil LH, Probst CM, Vidal NM, et al. Natural Plasmodium infection in monkeys in the state of Rondônia (Brazilian Western Amazon). Malar J. 2013;12:180.

35. Deane LM. Studies on simian malaria in Brazil. Bull World Health Organ. 1964;31:752-3

36. Flores-Mendoza C, Lourenço-de-Oliveira R. Bionomics of Anopheles aquasalis Curry 1932, in Guaraí, State of Rio de Janeiro, southeastern Brazil-I. Seasonal distribution and parity rates. Mem Inst Oswaldo Cruz. 1996;91:265-70.

37. Miguel RB. Estudo da infecção humana por Plasmodium spp no município de Guapimirim, estado do Rio de Janeiro. Fundação Oswaldo Cruz: MsD thesis. Instituto Oswaldo Cruz; 2011 
38. Curado I, Dos Santos MR, de Castro Duarte AM, Kirchgatter K, Branquinho MS, Bianchi Galati EA. Malaria epidemiology in low-endemicity areas of the Atlantic Forest in the Vale do Ribeira, São Paulo, Brazil. Acta Trop. 2006;100:54-62.

39. Tazi L, Ayala FJ. Unresolved direction of host transfer of Plasmodium vivax v. P. simium and P. malariae v. P. brasilianum. Infect Genet Evol. 2011;11:209-21.

40. Escalante AA, Barrio E, Ayala FJ. Evolutionary origin of human and primate malarias: evidence from the circumsporozoite protein gene. Mol Biol Evol. 1995;12:616-26.

41. Escalante AA, Cornejo OE, Freeland DE, Poe AC, Durrego E, Collins WE, et al. A monkey's tale: the origin of Plasmodium vivax as a human malaria parasite. Proc Natl Acad Sci U S A. 2005;102:1980-5.

42. Mu J, Joy DA, Duan J, Huang Y, Carlton J, Walker J, et al. Host switch leads to emergence of Plasmodium vivax malaria in humans. Mol Biol Evol. 2005;22:1686-93.

43. Carter R. Speculations on the origins of Plasmodium vivax malaria. Trends Parasitol. 2003;19:214-9.

44. Lim C, Tazi L, Ayala F. Plasmodium vivax: recent world expansion and genetic identity to Plasmodium simium. Proc Natl Acad Sci U S A. 2005;102:15523-8.

45. Cornejo OE, Escalante AA. The origin and age of Plasmodium vivax. Trends Parasitol. 2006;22:558-63.

46. Li J, Collins WE, Wirtz RA, Rathore D, Lal A, McCutchan TF. Geographic subdivision of the range of the malaria parasite Plasmodium vivax. Emerg Infect Dis. 2001;7:35-42.

47. Taylor JE, Pacheco MA, Bacon DJ, Beg MA, Machado RL, Fairhurst RM, et al. The evolutionary history of Plasmodium vivax as inferred from mitochondrial genomes: parasite genetic diversity in the Americas. Mol Biol Evol. 2013:30:2050-64.

48. Pacheco MA, Cranfield M, Cameron K, Escalante AA. Malarial parasite diversity in chimpanzees: the value of comparative approaches to ascertain the evolution of Plasmodium falciparum antigens. Malar J. 2013;12:328.

49. World Health Organization (WHO). MALVAC meeting 2004: evaluation of malaria vaccines. Pre-clinical evaluation group: optimizing the developmental pathway from the lab to the clinic. Switzerland: Report from a technical consultation at WHO/IVR Malaria Vaccine Advisory Committee meeting Montreux; 2004

\section{Submit your next manuscript to BioMed Central and take full advantage of:}

- Convenient online submission

- Thorough peer review

- No space constraints or color figure charges

- Immediate publication on acceptance

- Inclusion in PubMed, CAS, Scopus and Google Scholar

- Research which is freely available for redistribution 